\title{
ADDRESSING ENVIRONMENTAL CONTAMINATION THROUGH MARKET REGULATIONS: COMPARATIVE LESSONS FROM THE UNITED STATES AND THE EUROPEAN UNION
}

\author{
Alexandra Rosenbluth* \\ Latravia Smith**
}

\begin{abstract}
The existing legal frameworks in the United States (US) and the European Commission (EC) that regulate industrial chemicals represent divergent methods for controlling market entry, market restriction, and subsequent regulatory oversight when enforcement of these mechanisms fail. Contrary to the prevailing view that the Registration, Evaluation, Authorisation and Restriction of Chemicals (REACH) law, which amended the US Toxic Substances Control Act (TSCA), is the 'gold standard' for chemical regulation, the central premise of this article is that the Frank R. Lautenberg Chemical Safety Act for the 21st Century provides unique opportunities for preventing environmental releases from new and existing chemical substances, which amounts to, if not more stringent, than REACH.
\end{abstract}

Keywords: REACH, TSCA, Lautenberg, toxic chemicals.

DOI: http://dx.doi.org/10.4314/jsdlp.v7i2.1

* Graduated from the College of William \& Mary in 2015 where she majored in Government and Environmental Science \& Policy. Alexandra is now a community organizer at a small non-profit working on a just transition to renewable energy in Southern Oregon. During the summer of 2014, she served as a Policy Fellow at the U.S. Environmental Protection Agency's Office of Pollution Prevention \& Toxics.

** A student at Florida A\&M College of Law, Juris Doctor candidate, class of 2017. She is currently enrolled in the Center for International Law and Justice, which focuses on international and comparative law of developing nations. This past summer, she served as an Honors Law Clerk at the U.S. Environmental Protection Agency's Office of Enforcement Compliance Assurance. The information presented herein is a synthesis of their research. Note: the views and opinions expressed represent those of the authors and not necessarily those of the College of William \& Mary, Florida A\&M University College of Law, nor the U.S. Environmental Protection Agency. 


\section{INTRODUCTION}

The manufacturing, processing, use, and disposal of products that contain specific chemical properties are ongoing activities that ultimately lead to the presence of detectable levels of chemicals in the environment. ${ }^{1}$ Though the mere detection of a chemical does not amount to risk per se, its presence in environmental media and humans may indicate that specific regulatory provisions that are designed to minimize exposures to it have failed. ${ }^{2}$

Chemical manufacturers are required to comply with strict regulations that require limits or outright bans on the levels of chemicals that may enter the environment. For example, under the United States' Toxic Substances Control Act (hereinafter TSCA), the U.S. Environmental Protection Agency (hereinafter 'EPA' or the 'Agency') evaluates pre-manufacturing notifications (PMNs) for new chemical substances. PMN submissions require all available information on chemical identity, production volume, by-products, use, environmental release, disposal practices, human exposure, and existing available test information.

After its review, EPA may approve a PMN with specific limitations or bans (e.g., no releases to water). These types of restrictions are based on EPA's conclusion that '... the substance may present an unreasonable risk of injury to human health or the environment'. ${ }^{3}$ Similarly, under the European Commission's (EC) Registration, Evaluation, Authorization and Restriction of Chemicals (REACH) law, the European Chemicals Agency (ECHA) is tasked with ensuring compliance with strict specifications on whether acceptable environmental releases of chemicals may occur. As with TSCA, REACH

1 P. O. Darnerud, 'Toxic Effects of Brominated Flame Retardants in Man and in Wildlife' (2003) 29 Environment International 841.

2 Andreas Sjödin and others, 'Serum Concentrations of Polybrominated Diphenyl Ethers (PBDEs) and Polybrominated Biphenyl (PBB) in the United States Population: 2003-2004' (2008) 42 Environmental Science \& Technology Environ. Sci. Technol. 1377.

3 Reviewing New Chemicals under the Toxic Substances Control Act (TSCA) (EPA).www.epa.gov/oppt/newchems//pubs/possible.htm. Accessed on 18 September 2016. 
imposes greater scrutiny on compounds with certain properties (e.g., persistent, bio accumulative, and toxic). ${ }^{4,5}$ However, REACH established a framework that requires chemical manufacturers, rather than government officials (i.e., the European Chemicals Agency [ECHA]), to initially assess potential risks of concern to human health and the environment and to implement appropriate risk management measures. ${ }^{6}$

In theory, TSCA and REACH are intended to prevent chemical releases that may cause harm to human health or the environment. However, in practice, chemical releases do occur, even when outright bans, are established. Non-industry researchers typically provide the first lines of evidence for emerging environmental contamination (e.g., wildlife, water, and sediment) for specific classes of chemicals, particularly those that are persistent in the environment and possibly bio accumulate in humans or environmental receptors (e.g., brominated flame retardants and perfluorinated compounds). ${ }^{7,8}$ Governmental monitoring programmes also provide evidence of chemical contamination in humans. ${ }^{9}$ These sources are rarely capable of demonstrating that the levels detected may pose risks to human health

4 Policy Statement on a New Chemicals Category for Persistent, Bio accumulative, and Toxic (PBT) Chemicals (EPA). www.epa.gov/reviewing-new-chemicalsunder-toxic-substances-control-act-tsca/policy-statement-new-chemicals. Accessed 18 September 2016.

5 Commission Regulation (EU) 2016/26 of 13 Jan 2016 Amending Annex XVII to Regulation (EC) No 1907/2006 of the European Parliament and of the Council Concerning the Registration, Evaluation, Authorization and Restriction of Chemicals (REACH) as regards Nonylphenol Ethoxylates' (2007) 2016 Official Journal of the European Union 5. http://eur-lex.europa.eu/lexuriserv/ lexuriserv.do?uri=oj:1:2007:136:0003:0280:en:pdf.Accessed on 17 September 2016.

6 ibid 5, para 25 ('The responsibility to assess the risks and hazards of substances should be given, in the first place, to the natural or legal persons that manufacture or import substances, but only when they do so in quantities exceeding a certain volume, to enable them to carry the associated burden.').

7 Darnerud (n 1).

8 C Lau, 'Perfluorinated Compounds' (2012) 3 Experiential Supplementum Molecular, Clinical and Environmental Toxicology 47.

9 Sjödin (n 2). 
or the environment, although they do support that environmental releases and exposures are in fact occurring. ${ }^{10}$

TSCA and REACH represent divergent methods for controlling market entry, market restriction, and subsequent regulatory oversight when these mechanisms fail. Under TSCA, the EPA plays a role akin to having the 'guards watch the inmates', whereas under REACH, ECHA plays a role akin to having 'inmates guard the prison' with periodic check-ins by the guards. Though contrary to the prevailing view that REACH is the 'gold standard' for chemical regulation, the central premise of this article is that the Frank R. Lautenberg Chemical Safety Act for the 21st Century, which made important changes to TSCA, provides unique opportunities for preventing environmental releases from new and existing chemical substances, which amounts to, if not more stringent, than REACH.

This article continues in section 2 with an overview of the market entry provisions for new chemical substances under Lautenberg and REACH. Thereafter, section 3 focuses on the specific triggers that typically drive regulatory intervention, more stringent risk management measures, or even bans on existing chemical substances under these laws. The administrative and legal provisions that accompany market restrictions are also discussed. Section 4 moves forward with an evaluation of subsequent remedial measures in the U.S. and the E.C. that accompany media-specific regulation of existing chemicals. Finally, section 5 provides conclusions and recommendations on maximizing the utility of Lautenberg and international cooperation on Lautenberg and REACH.

\section{MARKET ENTRY OF NEW CHEMICAL SUBSTANCES IN THE US AND EC}

Regulatory agencies administer the laws that provide specific frameworks for evaluating new and existing substances. These are

10 Fourth National Report on Human Exposure to Environmental Chemicals (Centers for Disease Control and Prevention 13 June 2014). www.cdc.gov/ exposurereport/pdf/fourthreport.pdf. Accessed on 18 September 2016. The measurement of an environmental chemical in a person's blood or urine does not by itself mean that the chemical causes disease. Advances in analytical methods allow us to measure low levels of environmental chemicals in people, but separate studies of varying exposure levels and health effects are needed to determine whether such blood or urine levels result in disease. 
typically country- or region-specific, and have different data requirements depending on the regulatory status of the substance (e.g., new or existing substance). For example, in the U.S., manufacturers only need to submit health and safety information in their possession at the time of filing a PMN under TSCA, whereas in the EC, specific tests are mandated, regardless of the regulatory status, based on the intended production volume under REACH. In the discussion that follows, a general overview of Lautenberg and REACH is provided, along with the specific market-entry provisions of each.

\section{TSCA: New Chemical Substances}

After finding that human beings and the environment are exposed to large numbers of chemical substances and mixtures each year, ${ }^{11}$ the United States Congress passed TSCA in 1976 (hereinafter the 'Old' TSCA) with the purpose of preventing unreasonable risks of injury to health or the environment through the manufacture, processing, distribution in commerce, use, or disposal of chemical substances. ${ }^{12}$ At that time, there was 'widespread agreement' that the primary chemical management law of the United States was ineffective, outdated, and in need of reform. ${ }^{13}$ Moreover, the 'old' TSCA's problematic language effectively weakened the Agency's authority to regulate new chemicals by constructing burdensome procedural and evidentiary paradoxical dilemmas that were virtually impossible to overcome. ${ }^{14}$ Under the 'Old' TSCA, EPA was forbidden to regulate tens of thousands of chemicals that entered into commerce prior to 1976 without validation of their safety, ${ }^{15}$ including chemicals known to be

11 Toxic Substances Control Act 1976 (TSCA 1976), s 2(a)(1).

12 ibid s 2(a)(2).

13 Eve Gartner, 'Weak Laws and Weaker Governance Keep Toxic Chemicals on the Market' Earth Justice (17 July2016)http://earthjustice.org/blog/2016-april/ weak-laws-and-weaker-governance-keep-toxic-chemicals-on-themarket.accessed on 18 September 2016.

14 'Environmental Law Alert - Congress Passes Landmark Chemical Regulations Reform' Barnes \& Thornburg (10June 2016) <www.btlaw.com/environmentallaw-alert-congress-passes-landmark-chemical-regulations-reform-06-10-2016/ $>$ accessed 18 September 2016.

15 ibid.

16 James Hamblin, 'Toxic Substances Will Now Be Somewhat Regulated' The Atlantic (May 26, 2016) <www.theatlantic.com/health/archive/2016/05/toxicsubstances-control-act/484280/> accessed 18 September 2016. 
hazardous to human health and the environment. ${ }^{16}$

In June of 2016, Congress modernized the chemicals management law with the passage of the Frank R. Lautenberg Chemical Safety Act for the 21st Century (hereinafter Lautenberg). ${ }^{17}$ The passage of Lautenberg amended 'Old' TSCA and enhanced many of its deficient provisions by broadening the Agency's authority to, inter alia, better ensure the safety of all new and existing chemicals, require testing, reduce testing on vertebrates, and limit companies' ability to conceal information. ${ }^{18}$ The amendment strengthened human health protections by explicitly requiring protection of vulnerable populations, such as children, pregnant women, workers and the elderly. ${ }^{19}$

Lautenberg authorizes EPA to oversee the manufacture, use, and importation of chemical substances in the U.S. by requiring reporting, record keeping, and testing requirements, in addition to setting restrictions for 'production, importation, use and disposal' of chemical substances. ${ }^{20}$ Under the TSCA, a chemical substance is defined as any organic or inorganic substance of particular molecular identity not including mixtures, pesticides, tobacco, source materials, articles, or food additives. ${ }^{21}$ Furthermore, the term manufacture is defined to include not only manufacture and production, but also any import into the customs of the US. ${ }^{22}$

The manufacturing and processing notice requirements are laid out under Section 5 of TSCA. Manufacturers, importers, and processors are required to submit PMNs to the EPA administrator prior to manufacturing new chemical substances or significant new use notifications (SNUNs) for substances with significant new uses. ${ }^{23}$ EPA determines if a use is a significant new use by considering several factors, including:

17 The Frank R. Lautenberg Chemical Safety for the 21st Century Act (EPA) $<$ www.epa.gov/assessing-and-managing-chemicals-under-tsca/frank-rlautenberg-chemical-safety-21st-century-act> accessed 18 September 2016.

18 ibid.

19 Toxic Substance Control Act (codified as amended by Frank R. Lautenberg Chemical Safety for the 21st Century Act, Pub. L. No. 144-182, 2016). (Lautenberg 2016) s 2602(12).

20 Learn About the Toxic Substances Control Act (EPA) <www.epa.gov/assessingand-managing-chemicals-under-tsca/learn-about-toxic-substances-control-acttsca $>$ accessed 27 September 2016.

21 Lautenberg 2016 s 3(2)(A)(1).

22 ibid s 3(9). 
[T] he projected volume of manufacturing and processing of a chemical substance, the extent to which a use changes the type or form of exposure to human beings or the environment to a chemical substance, the extent to which a use increases the magnitude and duration of exposure of human beings or the environment to a chemical substance, and the reasonably anticipated manner and methods of manufacturing, processing, distribution in commerce, and disposal of a chemical substance. ${ }^{24}$

Under the 'Old' TSCA, after a PMN or SNUN was submitted, the PMN or SNUN was considered approved within 90 days unless EPA concluded that the PMN lacked sufficient data to determine the effects on health and the environment or whether it presented an unreasonable risk to human health or the environment. ${ }^{25}$ If both determinations were met, EPA could issue a proposed order to place specific restrictions on the chemical substance.

Lautenberg retained much of Section 5 of the TSCA, but made significant alterations that increased the Agency's obligation, while providing the Agency more flexibility in evaluating the safety of new chemicals. ${ }^{26}$ Before a new chemical can enter into commerce, Lautenberg explicitly requires the Agency to make one of three affirmative determinations concerning whether a new chemical or SNU presents or may present an 'unreasonable risks to a potentially exposed or susceptible subpopulation ...' and take the required actions. ${ }^{27}$

First, that the new chemical or SNU presents an unreasonable risk of injury to health or the environment, the Agency is required to regulate under Section 5(f). ${ }^{28}$ EPA must also promulgate a Significant New Use Rule (SNUR) or explain why it is not taking this step. ${ }^{29}$ An SNUR can be placed on a chemical after EPA reviews an initial PMN and places restrictions on that PMN in the form of a consent order with the submitting manufacturer. ${ }^{30}$ There are two types of New

23 ibid s 5(a)(1)(B)(i).

24 ibids 5(a)(2).

25 ibid s 5(e).

26 Congress Passes Landmark Chemical Regulations Reform (n 14).

27 TSCA 2016 s 5(a)(3).

28 ibid s 5(f)(2).

29 ibid.

30 ibid s 5(f)(4). 
Chemical SNURs: §5(e) SNURs and non-§5(e) SNURs. ${ }^{31}$ The §5(e) SNUR essentially mimics the terms and conditions of the consent order. Non-§5(e) SNURs are used when EPA has not found an unreasonable risk from the manufacture, processing, use, and disposal during the PMN review, but determines that potential new uses may increase the likelihood of an unreasonable risk through higher exposure(s). ${ }^{32}$

Under the second alternative, (1) if the information available is insufficient to permit a reasoned evaluation of the effects of the chemical; (2) or in the absence of sufficient information, the substance may present an unreasonable risk to health or the environment; (3) or such substance will be produced in substantial quantities and it either enters or may be anticipated to enter the environment in substantial quantities or there is or may be significant or substantial human exposure. ${ }^{33}$ If any of the determinations are met, the Agency is required to issue an order under Section 5(e) and to either implement a SNUR regulating use of the substance or explain why it is not taking this step. ${ }^{34}$ Lautenberg significantly broadened the scope of the Agency's regulatory authority by changing the first italicized 'or' from 'and'. ${ }^{35}$ This subtle revision allows EPA to regulate a chemical based solely on a lack of information.

The Administrator must require that testing be conducted if it determines that the chemical substances may present an unreasonable risk to the health or the environment, or lacks sufficient information. ${ }^{36}$ Section 4 of Lautenberg provides EPA more flexible authority to require testing by use of rule, orders, or consent agreement. ${ }^{37}$ Section 4(a)(4) specifies the use of a tiered screening and testing process unless available information supports moving on to more advanced testing. ${ }^{38}$ Lautenberg expanded Section 4(f) of the 'Old' TSCA to now require the EPA to expedite action when new information indicates that a chemical presents a significant risk to humans (e.g. chemicals that are

31 EPA Actions to Reduce Risk for New Chemicals under TSCA (EPA August 9, 2016) <www.epa.gov/reviewing-new-chemicals-under-toxic-substancescontrol-act-tsca/epa-actions-reduce-risk-new> accessed 18 September 2016. 32 ibid.

33 Lautenberg 2016 s 5(a)(3).

34 ibid s 4(e).

35 ibid s 5(a)(3).

36 ibid s 5(a).

37 ibid s 6(h)(1).

38 ibid s 4(a)(4). 
persistent, bio accumulative, and toxic). ${ }^{39}$ The 'Old' TSCA limited this provision to only chemical mixtures known to cause cancer, genetic mutations, or birth defects..$^{40}$ Lautenberg also added a new section to TSCA that requires the Agency to reduce and replace vertebrate animal testing to the extent practical when this can be scientifically justified ${ }^{41}$ and to develop and implement a plan to promote the use of alternative non-vertebrate animal-based testing methods. ${ }^{42}$

Third, that the new chemical or SNU is not likely to present an unreasonable risk, in which case, the submitter can commence manufacture or processing for SNU. ${ }^{43}$ If this determination is made, EPA is required to publish a statement of its finding. ${ }^{44}$ It is noteworthy to mention that in drafting Lautenberg, legislation neglected to define the key term 'unreasonable risks. ${ }^{45}$ This slight omission may be regarded as problematical for the Agency in future litigation in determining which risk are deemed reasonable or unreasonable.

The import and export of chemical substances to and from the US are also covered under the United State's Chemical Regulatory Act. Imports are considered a form of manufacturing as defined by Section 2 of TSCA; therefore, an imported chemical substance that fails to comply with the regulations shall be refused entry into U.S. customs territory. ${ }^{46}$ Companies importing chemical substances into the U.S. must notify the EPA if it is considered a significant new use in order to comply with TSCA Section 5(a). ${ }^{47}$ For exporting chemical substances, companies must only comply with Section 12 with regard to reporting/retaining information, unless it is proven that such substance is being manufactured, processed, or distributed for commerce in the US. ${ }^{48}$

In conclusion, EPA reviews new substance notifications (e.g., PMNs or SNUNs) and places specific testing or risk management provisions on market entry. The manufacture of a new chemical can only begin once EPA confirms it is likely to meet the safety 'protocols and

39 ibid s 5(a).

40 ibid.

41 ibid s 4(h)(1)(A).

42 ibid s 4(h)(1)(A)(i).

43 ibid s 5(a).

44 ibid.

45 ibid.

46 Lautenberg 2016 13(a).

47 ibid s 3(9).

48 ibid s 12(a). 
methodologies.' ${ }^{49}$ The Agency uses its expertise and experience with chemical categories to tailor testing requirements, including conducting studies under good laboratory practice (GLP) standards, ${ }^{50}$ to address information needs, rather than filling informational gaps. ${ }^{51}$ Under Lautenberg, EPA is empowered with broad authority to regulate new substances (e.g., production volume-based triggers or a ban pending upfront testing) or potentially to prohibit the manufacture of new substances altogether. At first blush, many of the provisions under Lautenberg, especially with regard to assessing potential risks from new chemicals, appear to be preserved under REACH. The differences that preclude such a conclusion will be addressed next.

\section{REACH: New Chemical Substances (non-phase-in substances)}

In June 2007, the EC adopted REACH in order to improve the protection of human health and the environment from chemicals manufactured and imported into the European Union. ${ }^{52} \mathrm{REACH}$ requires manufacturers and importers of chemicals to identify and manage the risks associated with all stages of the chemical's lifecycle by establishing procedures for collecting and assessing information on the substances. ${ }^{53}$

A company planning on manufacturing or importing a chemical in quantities greater than one ton per year must register the substance to ECHA. ${ }^{54}$ Article 10 of REACH lays out the information necessary to

49 ibid s 19(c)(2)(A), (B), in introductory provisions, substituted 'protocols and methodologies for the development of information' for 'standards for the development of test data'.

50 'Final Enforcement Response Policy (ERP) for the Toxic Substances Control Act (TSCA) Good Laboratory Practice (GLP) Regulations' EPA (1995) Memorandum dated 9 April 1985; From: A.E. Conroy II, Director, Office of Compliance Monitoring (EN-342); To: Addressees; Subject: Final TSCA GLP Enforcement Response Policy, $15 \mathrm{pp}$, at 'Study Invalidation', (EPA March 7, 2016) $<$ www.epa.gov/enforcement/final-enforcement-response-policy-erp-toxicsubstances-control-act-tsca-good-laboratory> accessed 18 September 2016.

51 TSCA New Chemicals Program (NCP) Chemical Categories (U.S. Environmental Protection Agency August 2010) <www.epa.gov/sites/production/files/ 201410/documents/ncp_chemical_categories_august_2010_version_0.pdf > accessed 18 September 2016.

52 REACH 2006 (n 5) 18, art 1, para 1.

53 ibid 18, art 1, para 3.

54 ibid 22, art. 6, para 1. 
submit a substance for general registration purposes. ${ }^{55}$ The registration of a chemical must include a technical dossier in addition to a chemical safety report (CSR). ${ }^{56}$ The identity of the manufacturer(s) or importer(s), the identity of the substance, guidance on safe use of the substance, study summaries on information derived from the application of Annexes VII to XI, an indication of review by an assessor chosen by the manufacturer or importer, and proposals for testing must be included in the technical dossier for proper registration. ${ }^{57}$

REACH has specific data requirements, including performance of studies under GLP standards, for substances depending on the annual production/import volume. ${ }^{58}$ The amounts relevant to varying levels of scrutiny include specific quantity triggers for new and existing substances produced/imported in quantities greater than 1, 10, 100, or 1,000 tons or more. ${ }^{59}$ The requirements build on each other, thus requirements for substances in quantities of 1,000 tons or more include the testing requirements of the lower quantities and so on.

A CSR is required for all substances registered for manufacture/ import once the quantities are up to 10 tons or more per year. ${ }^{60}$ The CSR documents the chemical safety assessment, which includes human health hazard assessment, physicochemical hazard assessment, environmental hazard assessment, PBT (i.e., persistent, bio accumulative, and toxic), and $\mathrm{vPvB}$ (i.e., very persistent and very bio accumulative) assessments. ${ }^{61}$ If assessments on human health hazards or $\mathrm{PBT} / \mathrm{vPvB}$ reveal that the substance meets the criteria to be classified as dangerous, then the safety assessment must include risk characterization and an exposure assessment with exposure scenarios and exposure estimation as well. ${ }^{62}$ The risk characterization consists of a comparison of the exposure of each human population likely to be

55 ibid 24, art 10.

56 ibid 24-25, art 10(a) and (b).

57 ibid.

58 ibid 7, para 37; see also: ibid 26, art 13, para 4 ('Eco toxicological and toxicological tests and analyses shall be carried out in compliance with the principles of good laboratory practice provided for in Directive 2004/10/EC or other international standards recognized as being equivalent...).

59 ibid 103-106 (Annex VII). See also 107-110 (Annex VIII), 111-115 (Annex IX), and 116-118 (Annex X).

50 ibid 26, art 14, para 1.

61 ibid 27, art 14, para 3 (a)-(d).

62 ibid 27, art 14, para 4 (a)-(b). 
exposed with derived no-effect levels (DNELs), a comparison of the predicted environmental concentration with predicted no-effect concentrations (PNECs), and an assessment of the likelihood and severity of an event occurring because of the physiochemical properties of the substance. ${ }^{63}$

In conclusion, REACH provides a tiered-testing approach for evaluating new and existing substances through mandatory testing, evaluation of risk(s), and implementation of risk management measures. In addition, study summaries or robust study summaries are required with regulatory dossiers for new and existing chemicals; however, full study reports with 'raw data' are not required. Market entry is premised on the outcome of risk determinations, which are initially made by the manufacturer, not the regulator (i.e., ECHA). ${ }^{64}$

The foregoing approach creates significant vulnerabilities with REACH because GLP standards, which include the requirements for documenting and archiving raw data, were initially developed to address research fraud that was occurring at contract laboratories. ${ }^{65}$ Oftentimes, errors or even outright fraud will go undetected, unless the 'raw data' from a study are available for comparison with summary data from the same study. ${ }^{66}$ As discussed in the next section, the irony of this approach is that manufacturers routinely request access to the underlying 'raw data' for studies that are used to drive market restrictions on their chemicals.

63 ibid 72, Annex I.

64 ibid 40, art 41, para 5 ('To ensure that registration dossiers comply with this Regulation, the Agency shall select a percentage of those dossiers, no lower than $5 \%$ of the total received by the Agency for each tonnage band, for compliance checking'.).

65 World Health Organization,GLP Guideline Handbook(World Health Organization) $328<$ www.who.int/tdr/publications/documents/glphandbook.pdf $>$ accessed 24 September 2016.

66 Joseph Haseman, 'Statistical Issues in the Analysis of Low-Dose Endocrine Disruptor Data' (2001) 61 Toxicological Sciences 201 ('There were also quality control issues with respect to the raw data provided us for statistical analysis. In two studies, the raw data had significant errors. In one case (involving two different studies from the same investigator) multiple pups were misassigned to litters, and multiple litters were misassigned to dosed groups. Another investigator inadvertently omitted entire blocks of data dealing with eight highdose animals. These errors were detected (and corrected) only because the Statistics Subpanel had access to summary data in published papers for comparative purposes.'). 


\section{MARKET RESTRICTION OF EXISTING CHEMICAL SUBSTANCES IN THE US AND THE EC}

Market restrictions on chemicals often start with the publication of findings, typically highly controversial ones, which indicate widespread environmental contamination and/or previously unidentified adverse health effects (e.g., developmental neurotoxicity). ${ }^{67}$ Brominated flameretardants are a contemporary example that satisfies each of these situations. The chemicals that make up this functional category of compounds is quite diverse, yet the category known as polybrominated diphenyl ethers (PBDEs) is by far the most known example.

Early reports of environmental contamination from decabromodiphenyl oxide (Deca), a PBDE, began in the 1980s. ${ }^{68}$ Subsequent findings of adverse health effects, including carcinogenicity in rats and mice, were reported in 1986. ${ }^{69}$ These findings, along with the publication of highly controversial research findings in 2003 that Deca causes developmental neurotoxicity, ${ }^{70,71}$ led to global pressure on Deca manufacturers to voluntarily phase out this compound, along with other PBDEs. ${ }^{72}$

67 Marek Banasik, 'The Perils of Failing to Critically Evaluate the Quality and Reliability of Peer-Reviewed Scientific Data: A Case Study with Decabromodiphenyl Ether.' (American Bar Science and Technology Newsletter January 2012) <www.americanbar.org/content/dam/aba/publications/ nr_newsletters/st/201201_st.pdf > accessed 24 September 2016.

68 Isao Watanabe and others, 'Confirmation of the Presence of the Flame Retardant Decabromobiphenyl Ether in River Sediment from Osaka, Japan' (1986) 36 Bulletin of Environmental Contamination and Toxicology 839.

69 'Toxicology and Carcinogenesis Studies of Decabromodiphenyl Oxide (CAS No. 1163-19-5) in F344/N Rats and B6C3F1 Mice (Feed Studies)' (U.S National Library of Medicine) <http://ntp.niehs.nih.gov/results/pubs/longterm/ reports/longterm/index.html> accessed 24 September 2016.

70 H. Viberg, 'Neurobehavioral Derangements in Adult Mice Receiving Decabrominated Diphenyl Ether (PBDE 209) during a Defined Period of Neonatal Brain Development' (2003) 76 Toxicological Sciences 112.

71 Banasik (n 67) 4.

72 DecaBDE Phase-out Initiative| Existing Chemicals (OPPT, EPA 2012 Deca BDE phase-out initiative, Existing Chemicals, EPA on 17 December 2009) <http:// hero.epa.gov/index.cfm/reference/download/reference_id/1003362> accessed 24 September 2016, as the result of negotiations with EPA, the two US producers of decabromodiphenyl ether (decaBDE), Albemarle Corporation and Chemtura Corporation, and the largest US importer, ICL Industrial Products, Inc., announced commitments to phase out decaBDE in the United States. The companies have committed to end production, importation, and sales of decaBDE for most uses in the United States by 31 December 2012, and to end all uses by the end of 2013'). 
The above example with Deca illustrates how existing chemicals may end up with market restrictions in the absence of formal regulatory intervention. This type of voluntary action can facilitate subsequent regulatory activities that allow regulators to ensure market restrictions. As discussed below, in the absence of cooperative agreements between regulators and the regulated community, the regulatory hurdles for restricting and potentially banning existing chemical substances under Lautenberg are far less arduous than they were under the 'Old' TSCA and REACH.

\section{TSCA: Existing Chemical Substances}

Chemicals, like Deca, that were in the stream of commerce prior to the enactment of TSCA (of 1976) were 'grandfathered in' and immediately added to the TSCA inventory as 'existing chemical substances.' For new chemical substances, once EPA completes its PMN evaluation and the submitter completes a Notice of Commencement of Manufacture or Import, the new chemical substance is added to the TSCA inventory and is then considered an existing chemical substance. ${ }^{73}$

Under the 'Old' TSCA, once a chemical was designated an existing chemical substance, EPA had no duty to evaluate the substance and its options for subsequent regulatory activity were limited and open to administrative and legal challenges. For example, under Section 4 of the 'Old' TSCA, EPA was required to make a statutory finding of 'data inadequacy' and 'testing is necessary' in order to require manufacturers, by test rule, to perform hazard or exposure testing. ${ }^{74}$ Section 4 of the 'Old' TSCA test rules were, however, time consuming and often took years to finalize because of the Agency's requirement to follow lengthy rule-making procedures set forth under the Administrative Procedure Act (APA), as well as the challenges that the regulated community may lodge. ${ }^{75}$ If and when a final TSCA Section 4 test rule was issued,

73 About the TSCA Chemical Substance Inventory $(E P A)<$ www.epa.gov/tscainventory/about-tsca-chemical-substance-inventory $>$ accessed 24 September 2016.

74 Data Development and Information Collection to Assess Risks (EPA) $<$ www.epa.gov/assessing-and-managing-chemicals-under-tsca/datadevelopment-and-information-collection-assess-risks $>$ accessed 24 September 2016.

75 The Administrative Procedure Act (APA 1946). 
the subsequent testing added additional months or years before EPA eventually obtained the required data. ${ }^{76}$

Under Section 6 of the 'Old' TSCA, if EPA found a 'reasonable basis to conclude' that the manufacture or importation of a chemical substance 'presents or will present' an unreasonable risk of injury to health or the environment, ${ }^{77}$ EPA could, in theory, take action to ban or limit the manufacture, processing or use of the chemical. As demonstrated in the following example, implementation of these actions under the pre-existing statutory language was problematic.

EPA previously attempted to issue a TSCA Section 6 rule that would have effectively banned asbestos, a known human carcinogen; ${ }^{78}$ however, the rule was challenged in court and, on appeal, the court overturned EPA's proposed rule for failing to consider a number of factors, required under the 'Old' TSCA, including, for example, the benefits of asbestos, the alternatives, and least burdensome measures. ${ }^{79}$ Since this time, EPA attempted, albeit unsuccessfully, to prepare additional TSCA Section 6 rules, including one for wheel balancing weights ${ }^{80}$ made of lead, a known human toxicant ${ }^{81}$ that arose from a TSCA Section 21 citizen petition. ${ }^{82}$

76 European Medicines Agency (European Medicines AgencyMay 19, 2011) <www.ema.europa.eu/ema/index.jsp?curl=pages/medicines/human/ medicines/002213/human_med_001465.jsp> accessed 24 September 2016. Note for example, a repeated dose 28-day oral toxicity study in rodents, performed under GLP standards and according to a validated test guideline, takes approximately one year to complete from the initial drafting of the study protocol to issuing the final quality assured study report.

77 TSCA 1976, s 6.

78 NTP (National Toxicology Program). 2014. Report on Carcinogens, Thirteenth Edition. Research Triangle Park, NC: U.S. Department of Health and Human Services, Public Health Service. <http://ntp.niehs.nih.gov/pubhealth/roc/ roc13/> accessed 24 September 2016.

79 Corrosion Proof Fittings v. EPA 1991947 F.2d 1201 (5th Cir. 1991).

80. 'Lead Wheel Weights; Regulatory Investigation - Reg DaRRT | Laws \&Amp; Regulations | US EPA' (EPA) < https://yosemite.epa.gov/opei/rulegate.nsf/ byrin/2070-aj64> accessed 27 September 2016.

81 NTP Monograph on Health Effects of Low-Level Lead <http:// ntp.niehs.nih.gov/ntp/ohat/lead/final/monographhealtheffects lowlevellead_ newissn_508.pdf $>$ accessed 27 September 2016.

82 Chemicals under the Toxic Substances Control Act (TSCA) (EPA) < https:// www.epa.gov/chemicals-under-tsca > accessed 24 September 2016. One-page response letter dated 26 August 2009; From: Owens, S. (Assistant Administrator, Office of Prevention, Pesticides and Toxic Substances); To: Gearhart, J. (Ecology Center) and Neltner, T. (Sierra Club). 
The limitations on EPA's ability to regulate existing chemical substances have focused narrowly on Section 6 actions and formed the basis of TSCA reform initiatives. Section 4(a)(2) of Lautenberg grants EPA with a newfound authority to perform risk evaluations for existing chemicals under Section 6(b), ${ }^{83}$ as well as use rules, orders, and consent agreements to obtain testing for review of PMNs and SNUNs under Section $5 .{ }^{84}$ Lautenberg revisions removed the challenging language from Section 6 that required existing chemicals be regulated by the 'least burdensome requirement' 85 and mandates the evaluation of existing chemicals by establishing new risk-based safety protocols and methodologies to determine whether the chemical presents any 'unreasonable risks' to public health or the environment. ${ }^{86}$

Section 6(a) of Lautenberg now requires that EPA classify chemicals as high or low priority substances to determine which chemicals it will prioritize for risk-based safety assessment. ${ }^{87}$ The process requires EPA to perform a risk-based screening of chemicals relying on factors such as 'hazard and exposure potential, persistence and bioaccumulation, and storage near significant sources of drinking water.' ${ }^{88}$ Low-priority designations do not require any further testing. ${ }^{89}$ Observably, upon the discovery of new information, low-priority chemicals can be reclassified as high-priority. ${ }^{90}$

High-priority chemicals are chemicals that may 'present an unreasonable risk of injury to health or the environment due to potential hazard and route of exposure, including to susceptible subpopulations. ${ }^{91}$ Lautenberg stipulates risk evaluations to be performed on all high-priority chemicals, designating high priority to 'highly persistent/highly bio-accumulative chemicals on the 2014 TSCA Work Plan list and chemicals that are known human carcinogens and have high acute and chronic toxicity. ${ }^{92}$ After safety assessment, if EPA determines that a chemical poses an unreasonable risk, it must pass a

83 Lautenberg 2016 s 6(6)(b)

84 ibid.

85 ibid s (6)(a).

86 ibid s (6)(a).

87 ibid s 6(b)(1)(A).

88 ibid.

89 ibid s 6(b)(1)(B)(ii).

90 ibid.

91 ibid s 6(b)(1)(B)(i).

92 ibid s 6(b)(20(A). 
regulation to reduce the risk through use of labelling restrictions, bans, phase-outs, or restrictions on usage. ${ }^{93}$ Lautenberg specifies aggressive timelines for each step of the assessment process. The entire risk evaluation process must be completed three and a half years after its commencement, with a possible six-month extension. ${ }^{94}$

Under the 'Old' TSCA, costs could be considered when initially assessing risk; ${ }^{95}$ however, under Section 6(b)(4) of Lautenberg, EPA may not factor in costs or other non-risk factors during the initial assessment. ${ }^{96}$ If EPA decides to restrict a chemical, Lautenberg does require EPA to conduct a cost-benefit analysis to determine risk management options in which costs and the availability of alternatives must be taken into account. ${ }^{97}$ EPA must promulgate risk management actions within two years after the completion of the risk evaluations, with a possible extension of up to an additional two years. ${ }^{98}$

Many proponents of TSCA reform favoured the regulatory paradigm enforced in the EC under REACH. As indicated below, REACH offers a clear and transparent approach to regulating existing substances because it captures substances that were grandfathered under the EC's previous chemical control law. Recall that REACH does not require the submission of full study reports in support of regulatory dossiers. Rather, it requires the submission of robust data summaries, which lack the underlying 'raw data'. Furthermore, the lock step system of addressing regulatory disputes in the EC suffers from the same protracted timelines that accompany rule making initiatives under Section 4 of the 'Old' TSCA. ${ }^{99}$

\section{REACH: Existing Chemical Substances (phase-in substances)}

In the European Union, new and existing chemical substances are evaluated identically. The only difference between the two is the established deadlines for submitting dossiers on specific existing

93 ibid s 6(d)(1)(D).

94 ibid s 6(b)(2)(A).

95 ibid s (6)(a).

96 ibid s 6(b)(4)(A).

97 ibid s 6(b)(2)(C).

98 ibid s 8(b)(4)(E) (ii)(I).

99 S.Haukka, 'Decision of the Board of Appeal of the European Chemicals Agency' (ECHA April 2, 2014) <http://echa.europa.eu/documents/10162/13575/a008-2012_boa_decision_en.pdf > accessed 24 September 2016. 
chemicals. ${ }^{100}$ Furthermore, registrants of the same existing chemical substances are required to form substance information exchange fora (SIEF). ${ }^{101}$ Within a SIEF, the registrants bring forward any data they have and provide compensation to the specific data owners in the SIEF. This approach reduces the number of vertebrate animals used for testing that may have otherwise been used had each manufacturer filed a separate registration. ${ }^{102}$

Once a chemical is registered under REACH, chemicals may undergo evaluation, ${ }^{103}$ at which point, a Member State of the European Union serves as the Competent Authority ${ }^{104}$ for evaluating the registration dossier and issuing a recommendation to ECHA, which will, in turn, informs the EC, the registrant, and other Member States within 12 months after initiation of evaluation, or within 12 months after the receipt of further information requested in support of evaluation. ${ }^{105,106}$

Mechanisms for judicial review are available when disagreements arise on the relevance and choice of specific data to use for identifying risks and appropriate risk management measures. For example, once a registrant submits a dossier to ECHA, the relevant Member States (e.g., those where manufacturing takes place) are informed of ECHA's initial evaluation and are afforded the opportunity to comment. ${ }^{107}$ If a registrant disagrees with ECHA's draft decision (e.g., identified as a substance of very high concern and recommendation [SVHC] for authorization), the registrant may challenge the decision in the form of an appeal to the Board of Appeal. ${ }^{108}$ Once filed, the appeal has a suspensive effect on the disputed decision. ${ }^{109}$ If the appeal is denied, the registrant may bring an action before the Court of First Instance or the Court of Justice of the European Union. ${ }^{110}$

In conclusion, REACH offers a transparent and structured approach for evaluating regulatory dossiers and for handling regulatory disputes;

100 REACH (2006) (n 5) 126, art 43, para 2 (a)-(c).

101 ibid 34, art 29, para 1.

102 ibid 8, para 49.

103 ibid 40, art 41, para 5.

104 ibid 41, art 45, para 1.

105 ibid 41, art 46, para 4.

106 ibid 42, art 48.

107 ibid 43, art 51, para 2.

108 ibid 59, art. 91 para 1.

109 ibid 59, art 91 para 2.

110 ibid 59, art 94 para 1. 
however, time-consuming procedural steps, which apply to both existing and new chemical substances, accompany this structured system. Similarly, timely procedural obstacles hindered the evaluation and regulation of existing chemical substances under the 'Old' TSCA. Unlike REACH, new and existing chemical substance evaluations under Lautenberg are virtually unhindered by these types of delays.

\section{ENFORCEMENT AND COMPLIANCE OF RESTRICTIONS PLACED ON EXISTING CHEMICAL SUBSTANCES IN THE US AND THE EC}

Regardless of the types of restrictions placed on chemical substances, the subsequent regulatory approaches used for addressing environmental contamination in the US and the EC provide insight on the disconnect that exists between the pre- and post-market regulation of chemical substances under registration laws (e.g., TSCA and REACH) versus media-specific laws (e.g., Clean Water Act). In this context, contamination refers to the identification of a regulated chemical in a medium (e.g., water) where the chemical is banned or exceeds an allowable level. In both jurisdictions, retroactive approaches are used for addressing contamination, despite opportunities for proactive enforcement and compliance of restrictions established under the registration laws. As discussed in this section, Lautenberg and REACH provide several opportunities for regulators and citizens to interject and ensure compliance with pre-existing restrictions (e.g., Lautenberg Section 5(e) SNURs), which could serve to avoid the time and costs with establishing the downstream retroactive regulatory approaches that are typically pursued.

\section{United States of America}

Many chemicals identified as contaminants of emerging concern were exempted under the 'Old' TSCA in the sense that they were grandfathered in when TSCA was enacted. ${ }^{111,112}$ For these classes of compounds (e.g., PBDEs and some perfluorinated compounds), TSCA

111 Contaminants of Emerging Concern (CECs) in Fish: Polybrominated Diphenyl Ethers (PBDEs), EPA-820-F-13-003 (EPA) <http://nepis.epa.gov/exe/ zypurl.cgi?dockey $=$ p100h2mp.txt $>$ accessed 27 September 2016.

112 ibid. 
Section 5(e) SNURs generally do not exist and their regulation would have proceeded only after they were detected in the environment through media-specific laws, but only after years of data collection and a lengthy rule-making process. Specific requirements exist that preclude a timely response to concerns over environmental contaminants. For example, under the Clean Water Act, the Agency must take into account specific factors to list additional toxic pollutants ${ }^{113}$ and make a statutory finding that the contamination occurred due to a direct discharge from a point source into navigable waters where the polluter either: 1) did not obtain a National Pollutant Discharge Elimination System (NPDES) permit, or 2) exceeded the discharge limit for a permitted pollutant. ${ }^{114}$ However, environmental releases may go undetected when no point source monitoring requirements exist or when releases occur in a diffuse manner that does not require NPDES permits, as discussed next in a real world example.

In 1989, a manufacturer of Deca submitted a PMN to EPA for decabromodiphenyl ethane, a compound that is not a PBDE, but is structurally similar to Deca. ${ }^{115}$ EPA entered into a consent order with the submitter and approved the PMN. Subsequently, in 1993, EPA issued a TSCA §5(e)-SNUR that called for 'no release to US waters', which applied to the manufacturer and its customers. ${ }^{116}$ In 2012, a group of non-industry researchers published findings showing that sediment concentrations of decabromodiphenyl ethane had increased over the past couple of decades near the facilities that manufacture decabromodiphenyl ethane. ${ }^{117}$

113 Federal Water Pollution Control Act (FWPCA 1972) (FWPCA; a.k.a., the Clean Water Act), 33 U.S.C. 1251 et seq., as amended through P.L. 107-303, November 27, 2002), s 307(a) ('The Administrator in publishing any revised list, including the addition or removal of any pollutant from such list, shall take into account the toxicity of the pollutant, its persistence, degradability, the usual or potential presence of the affected organisms in any waters, the importance of the affected organisms, and the nature and extent of the effect of the toxic pollutant on such organisms.').

114 ibid 88 s 303(a).

115 Steve Dungey, 'Environmental Risk Evaluation Report: 1,1'- (Ethane-1,2Diyl)Bis[Penta-Bromobenzene]' ( Environment Agency Rio House 2007) rep <www.gov.uk/government/uploads/system/uploads/attachment_data/file/ 290840/scho0507bmor-e-e.pdf $>$ accessed 18 September 2016.

116 ibid 19.

177 Hua Wei and others, 'Correction to Polybromodiphenyl Ethers and Decabromodiphenyl Ethane in Aquatic Sediments from Southern and Eastern Arkansas, United States' (2012) 46, Environmental Science \& Technology, 8017. 
The above example represents the theory (i.e., no water releases) versus the reality (i.e., water releases occur) of compliance with consent orders or $\S 5(\mathrm{e})$-SNURs. It also provides insight on three specific regulatory options that exist under this type of situation. First, a section of Lautenberg that had not been used with §5(e)-SNURs under TSCA, but fits specifically within the rubric of restrictions on new chemical substances is the enforcement provisions under Section 16. Under this section, EPA's Administrator may levy civil penalties of up to US\$37,500 per day, formerly US $\$ 25,000$ per day under the TSCA, for continuing violations of Lautenberg, ${ }^{118}$ including '... any requirement prescribed by section $5 \ldots$ any rule promulgated or order issued under section 5 [e.g., §5(e) SNUR]....'119 Therefore, Section 16 of Lautenberg represents a unique mechanism for bridging environmental monitoring information, like those reported by Wei et al. (2012), ${ }^{120}$ with enforcement initiatives to improve compliance. Arguably, this approach is retroactive, although it represents a more expeditious approach than addressing environmental releases through media-specific regulations.

A second option, related to option 1 , includes citizen actions under the False Claims Act (FCA). ${ }^{121}$ Under the FCA, a party who knowingly submits false claims to the government is liable for treble the damages in addition to a fine that ranges from US $\$ 5,000$ to US $\$ 11,000$ per violation. ${ }^{122}$ Furthermore, Section 3730 (b) of the FCA authorizes private citizens, referred as the 'realtor', to file a suit on behalf of the government, or a 'qui tam' action. In qui tam actions, if the court finds the defendant guilty the realtor may receive between 15 and 30 per cent depending on if the government intervenes or not. ${ }^{123}$ Under the $\S 5(\mathrm{e})$-SNUR scenario, the false claim would relate to the manufacturer's failure to notify EPA of its non-compliance. Though the utility of using the FCA for improving regulatory compliance is not routinely used,

118 Lautenberg 2016 s 16(a).

119 ibid s 16.

120 Wei (n 117).

121 False Claims Act 1986.

122 'The False Claims Act: A Primer - Justice Justice.gov (22 April 2011) $<$ www.justice.gov/sites/default/files/civil/legacy/2011/04/22/cfrauds_fca_primer.pdf $>$ accessed 18 September 2016.

123 ibid 3. 
successful cases have been filed, ${ }^{124}$ including a pending case against a chemical manufacturer for failing to notify the Agency of substantial risk information under Section 8 of TSCA. ${ }^{125}$

A final option is to include monitoring requirements under consent orders or §5(e)-SNURs. Under this option, monthly monitoring could be tied to the general NPDES permits, whereby the registrant analyses for the TSCA-regulated chemical, along with the chemicals included on the NPDES permit, to ensure compliance.

As indicated in the foregoing discussion, Lautenberg establishes clear restrictions on chemical substances that, if complied with, can ensure environmental protection. Observably, regardless of the restrictions placed on chemical substances, compliance monitoring and enforcement activities are critical for ensuring that non-compliant facilities are brought into compliance. In the absence of these activities, environmental contamination may go on for years or even decades, before media-specific approaches for addressing the contamination are initiated at the state or regional level. ${ }^{126}$ However, as discussed below, the interplay between REACH and the EC's media-specific laws (e.g., the Water Framework Directive) are seemingly slanted towards future retroactive regulatory initiatives to address environmental contamination.

\section{European Commission}

The European Union employs a fundamentally different framework and procedure, than the US, for ensuring compliance and enforcement with pre-established environmental release values. REACH requires registrants to derive PNECs for evaluating potential risks to environmental compartments (e.g., surface water and sediment);

124 US ex rel David Tilson v Lockheed Martin et al (United States District Court for the District of the Virgin Islands, St Croix Division)Realtors sued defendants for False Claims under the Resources Conservation and Recovery Act (RCRA) in addition to their government contracts.

125 Tom Aswell, 'Whistleblower Suit Claims DuPont's Burnside Plant Conceals Carcinogenic Sulfur Trioxide (SO3) Leak More than Two Years' (Louisiana Voice 31May 2014) < https://louisianavoice.com/2014/03/31/whistleblowerclaims-duponts-burnside-plant-has-been-leaking-carcinogenic-sulfer-trioxidemore-than-two-years/> accessed 18 September 2016.

126 K. Vorkamp and F. F. Rigét, 'A Review of New and Current-Use Contaminants in the Arctic Environment: Evidence of Long-Range Transport and Indications of Bioaccumulation' (2014) 111 Chemosphere 379. 
however, as discussed previously, this approach lacks the pre-market entry evaluation and review from regulatory scientists, as performed in the US, before a chemical substance enters the stream of commerce. To compound matters, the values derived for REACH dossiers may form the basis of monitoring thresholds from which listing decisions are made or not made under the primary water regulations in Europe (i.e., the Water Framework Directive [WFD]). ${ }^{127}$

The WFD was based on geographical and hydrological boundaries that led to the formation of river basins, rather than national/political boundaries. This directive represents a holistic framework for bringing waters in the European Union into 'good water status'. ${ }^{128}$ Under Article 16 of the WFD, the EC is required to identify priority substances (i.e., those presenting a significant risk) based on, for example, Council Regulation (EEC) No 793/93 (repealed and replaced by REACH). ${ }^{129,130,131}$ In 2001, the EC identified its first list of 33 priority substances $^{132}$ and, in 2008, amended the WFD, and developed environmental quality standards (EQSs). ${ }^{133}$ PBDEs were identified among the list of priority substances and had the lowest EQSs derived from the list. ${ }^{134}$

127 'Directive 2000/60/EC of the European Parliament and of the Council of 23 October 2000 Establishing a Framework for Community Action in the Field of Water Policy (OJ L 327 22.12.2000 p. 1)' Documents in European Community Environmental Law 879.

128 ibid 3, para 26.

129 ibid 17, art 16.

130 EC 1993 Council Regulation (EEC) No 793/93 of 23 March 1993 on the evaluation and control of risks of existing substances. Official Journal of the European Communities, L084, 75.

131 REACH 2006 (n 5) 3.

132 EC (2001) Decision No 2455/2001/EC of the European Parliament and of the Council of 20 November 2001 establishing the list of priority substances in the field of water policy and amending Directive 2000/60/EC. Official Journal of the European Communities, L331, 5 pp., at pp. 4-5, Annex X.

133 EC (2008) Directive 2008/105/EC of the European Parliament and of the Council of 16 December 2008 on environmental quality standards in the field of water policy, amending and subsequently repealing Council Directives 82/ 176/EEC, 83/513/EEC, 84/156/EEC, 84/491/EEC, 86/280/EEC and amending Directive 2000/60/EC of the European Parliament and of the Council. Official Journal of the European Union, 92, Annex I.

134 ibid, Annex I (Note, the EQS for 'Brominated diphenylether [i.e., PBDEs]' is $0.0002 \mu \mathrm{g} / \mathrm{L}$; one other compound (i.e., 'Tributyltin compounds') had an ECQ equal to this value). 
The WFD requires the EC to review the priority substance list every four years and consider other substances for possible inclusion. In 2006, the underlying basis for designating chemical substances as priority substances (Council Regulation (EEC) No 793/93), under Article 16 of the WFD, was repealed and replaced by REACH. This created a potential void with how chemicals were identified and evaluated under the WFD, given that Article 8 of the amended WFD required the EC to identify a new list of priority substances and to 'set corresponding EQS [s] for surface water, sediment or biota, as appropriate'. ${ }^{135}$ Through consultations, the EC concluded that EQSs were identified and set based on criteria, which were consistent with the criteria for SVHCs under REACH, and proposed amendment of the WFD once again. ${ }^{136,137}$

It follows from the above that the WFD and accompanying amendments represent a holistic approach for improving water quality in the European Union. Notably, with the passage of REACH and the ensuing proposal to use SVHC designation as a basis for identifying priority substances under the WFD, there are two immediate concerns that ensue. First, ECHA must select a chemical substance for evaluation. Then, after consultation through a community rolling action plan, it must be identified as an SVHC with a recommendation for authorization. At this stage, the registrant may lodge an article 92 challenge. Depending on the outcome, it may take several years before the chemical substance is selected for listing as a priority substance under the amended WFD. Second, penalties for non-compliance under the WFD are qualitatively described as those that are 'effective, proportionate, and dissuasive...'138 The same qualitative language is used in REACH for non-compliance. ${ }^{139}$ Neither regulation specifies actual monetary penalties for non-compliance.

135 ibid 90, art 8.

136 EC (2011) Proposal for a Directive of the European Parliament and of the Council amending Directives 2000/60/EC and 2008/105/EC as regards priority substances in the field of water policy, COM(2011) 876 final, Brussels, 31.1.2012, 35 .

137 ibid 33 (Note, the new list of priority substances include one, non-PBDE, brominated flame retardant and perfluorinated compounds.).

138 EC (2000) (n 127) 20, art 23.

139 REACH (2006) (n 5) 66, art 126. 


\section{CONCLUSIONS}

Observably, there are strengths and weaknesses with how TSCA and REACH authorize the regulation of new and existing chemical substances. EPA experienced several failures when attempting to ban existing chemical substances under Section 6 of 'Old' TSCA. However, EPA has had significant successes with implementing de facto bans on the manufacturing and importing of specific chemical substances into the US by using other sections of TSCA. For example, in 2004, EPA successfully negotiated a voluntary agreement with the sole manufacturer of two PBDEs (i.e., pentabromodiphenyl ether and octabromodiphenyl ether) to phase out these compounds by 31 December 2004. ${ }^{140}$ Thereafter, EPA issued SNURs on these chemicals, which ensured that these compounds would not be manufactured or imported into the US without undergoing an evaluation by EPA. ${ }^{141}$ Furthermore, the manufacturers of Deca voluntarily phased out and ceased manufacturing/importing this compound on 31 December 2013. This is noteworthy given that the EC completed a definitive risk assessment on Deca in 2002, ${ }^{142}$ yet Deca was not listed under ECHA's candidate list for authorization under REACH until 29 November 2012. ${ }^{143}$

140 Polybrominated Diphenylethers (PBDEs) Significant New Use Rules (SNUR) EPA (19May 2016) <www.epa.gov/assessing-and-managing-chemicals-undertsca/polybrominated-diphenylethers-pbdes-significant-new-use $>$ accessed 24 September 2016.

141 By avoiding a significant new use, a firm can avoid submission and testing costs but may incur other compliance costs. The firm may also incur 'hidden' costs; for example, it could forego profitable opportunities to use the chemical substance in an application that would be a significant new use or limit production volume to avoid a significant new use. Costs are estimated at the firm level and reflect the burden of a SNUR on the firms that make a submission. The hidden costs to the firms that do not make a submission are not quantified. EPA receives only a handful of SNUNs per year due to SNURs. However, the number of firms affected by not making submissions to EPA is not known; therefore, costs are not aggregated across the affected entities, 'Certain Polybrominated Diphenylethers; Significant New Use Rule and Test Rule' (Federal Register February 2012) <www.federalregister.gov/articles/2012/04/02/ 2012-7195/certain-polybrominated-diphenylethers-significant-new-use-ruleand-test-rule $>$ accessed 27 September 2016.

142 European Union Risk Assessment Report - Echa.europa.eu (European Chemicals Agency)<http://echa.europa.eu/documents/10162/6434698/orats_final_ rar_bispentabromophenylether_en.pdf $>$ accessed 24 September $201 \overline{6}$.

143 Agreement of the Member State Committee on the identification of bis(pentabromophenyl) ether [Decabromodiphenyl ether] as substance of very high concern according to articles 57 and 59 of Regulation (EC) 1907/ 
Beyond the notification/registration laws, the US and the EC have post hoc media-specific laws, which propagate failed enforcement (e.g., TSCA) or oversight (e.g., REACH) that occurs during the notification/ registration process. Ironically, these failures continue despite the greater stringency required to list and regulate a chemical under mediaspecific laws. The CWA and the WFD have burdens of proof, including extensive data requirements and timely processes, before meaningful steps can be taken to address environmental contamination.

The foregoing examples support the need for changing the chemicals regulation debate to a non-partisan focus with the recognition that chemical exposures are not Democratic or Republican in nature, but rather issues that affect populations. The EC's WFD considers this and represents a significant step forward with addressing chemicals management. However a significant caveat applies following no requirement to provide full study reports, including 'raw data', as supporting information. This lack of data standard will likely weaken the value and utility for identifying SVHCs under REACH, as well as priority substances under the WFD.

The concern here is that this approach appears to favour the regulatory 'gamesmanship' that can drive business-based decisions. For example, if a registrant submits robust summaries under REACH that down play or mask the potential hazards of a compound, and then uses these data to calculate PNECs, the chances of detection are rather small. Of course, this assumes that a registrant's dossier is part of the five per cent of dossiers evaluated by ECHA, that ECHA will request the full study reports as a part of its evaluation, and that ECHA will review them and identify any false reporting.

Though provided as hypothetical, the above scenario is significant because chemical regulations have global impacts, and a failure under REACH may absolve successes under Lautenberg and vice versa. Therefore, greater interaction between regulatory agencies needs to take place when evaluating the potential risks of chemical substances. There have been some efforts in this direction. For example, on 17 December 2010, ECHA and EPA signed a statement of intent (SOI) for sharing data across jurisdictions, while at the same time, preserving

2006 (European Chemicals Agency 19 December 2012) <http://echa. europa.eu/documents/10162/7183371/agreement_deca_bde_en.pdf $>$ accessed 24 September 2016. 
confidential business information (CBI). ${ }^{144}$ Notably, there was no indication that EPA approached or collaborated with ECHA on its recent existing chemical substance evaluations. ${ }^{145}$ Given the prominence of EPA's assessments, it is doubtful that there is any cross-talk between these agencies on lower priority or lower visibility projects, let alone those that contain CBI (i.e., PMNs or non-phase in substances). Furthermore, there is no indication that any effort has been made to compare the robust summaries submitted under REACH with EPA's published substantial risk notifications under Section 8(e) of TSCA. It appears as though this would be a good starting point for identifying clandestine groups that may have tweaked robust summaries to avoid more stringent risk management measures in the European Union.

In conclusion, Lautenberg made important changes to TSCA, which appear to provide greater pre- and post-market scrutiny and restriction than REACH. The specific provisions under Lautenberg Section 5(e) SNURs capture media-specific releases, without the restrictions that accompany media-specific regulations (e.g., Clean Water Act and point source releases). Observably, once chemicals enter the environment, they are no longer a local problem and oftentimes become regional or even global problems. Therefore, it is critical that regulatory agencies around the world consider an international collaborative approach when drafting and harmonizing chemical control laws. This will ensure that chemical substances regulations are coordinated, consistent, and strategic which, in turn, will help assure the efficacy of laws among nations. Combining efforts internationally will make certain the strengths and weaknesses, like those identified herein under TSCA/ Lautenberg and REACH, and they will be addressed through drafting local regulatory frameworks with the understanding and intent that they will influence global issues.

144 Statement of Intent between the European Chemicals Agency (ECHA) and the United States Environmental Protection Agency, Office of Chemical Safety and Pollution Prevention's (OCSPP) Office of Pollution Prevention and Toxics (OPPT) and Office of Research and Development's (ORD) National Center for Computational Toxicology (NCCT), Related to Chemical Management Activities <http://echa.europa.eu/documents/10162/13606/soi_echa_us_epa_ 20101220_en.pdf $>$ accessed 24 September 2016.

1452014 Assessments for TSCA Work Plan Chemicals (EPA) <www.epa.gov/ assessing-and-managing-chemicals-under-tsca/assessments-tsca-work-planchemicals $>$ accessed 24 September 2016. 